\title{
Simultaneous Requirements for Hes1 in Retinal Neurogenesis and Optic Cup-Stalk Boundary Maintenance
}

\author{
Bernadett Bosze, ${ }^{1}$ Myung-Soon Moon, ${ }^{1}$ Ryoichiro Kageyama, ${ }^{2,3}$ and ${ }^{\circledR N a d e a n}$ L. Brown ${ }^{1}$ \\ ${ }^{1}$ Department of Cell Biology and Human Anatomy, University of California Davis, Davis, California 95616, ${ }^{2}$ Institute for Frontier Life and Medical Sciences, \\ Kyoto University, Kyoto 606-8507 Japan, and 'Institute for Integrated Cell-Material Sciences, Kyoto University, Kyoto 606-8501, Japan
}

\begin{abstract}
The bHLH transcription factor Hes1 is a key downstream effector for the Notch signaling pathway. During embryogenesis neural progenitors express low levels of Hes1 in an oscillating pattern, whereas glial brain boundary regions (e.g., isthmus) have high, sustained Hes1 levels that suppress neuronal fates. Here, we show that in the embryonic mouse retina, the optic nerve head and stalk express high Hes1, with the ONH constituting a boundary between the neural retina and glial cells that ultimately line the optic stalk. Using two Cre drivers with distinct spatiotemporal expression we conditionally inactivated Hes 1 , to delineate the requirements for this transcriptional repressor during retinal neurogenesis versus patterning of the optic cup and stalk. Throughout retinal neurogenesis, Hes 1 maintains proliferation and blocks retinal ganglion cell formation, but surprisingly we found it also promotes cone photoreceptor genesis. In the postnatal eye, Hes1 inactivation with Rax-Cre resulted in increased bipolar neurons and a mispositioning of Müller glia. Our results indicate that Notch pathway regulation of cone genesis is more complex than previously assumed, and reveal a novel role for Hes 1 in maintaining the optic cup-stalk boundary.
\end{abstract}

Key words: bHLH; gliogenesis; Hes1; neurogenesis; Notch signaling; retina

\section{Significance Statement}

The bHLH repressor Hes1 regulates the timing of neurogenesis, rate of progenitor cell division, gliogenesis, and maintains tissue compartment boundaries. This study expands current eye development models by showing Notch-independent roles for Hes 1 in the developing optic nerve head (ONH). Defects in ONH formation result in optic nerve coloboma; our work now inserts Hes1 into the genetic hierarchy regulating optic fissure closure. Given that Hes 1 acts analogously in the $\mathrm{ONH}$ as the brain isthmus, it prompts future investigation of the $\mathrm{ONH}$ as a signaling factor center, or local organizer. Embryonic development of the $\mathrm{ONH}$ region has been poorly studied, which is surprising given it is where the pan-ocular disease glaucoma is widely believed to inflict damage on RGC axons.

\section{Introduction}

The mammalian retina contains six neuronal and one glial cell class. They are generated in a conserved, overlapping birth order, with retinal ganglion cells (RGCs), amacrines, horizontals and

Received Sept. 30, 2019; revised Jan. 2, 2020; accepted Jan. 7, 2020.

Author contributions: B.B. and N.L.B. designed research; B.B. and M.-S.M. performed research; B.B., M.-S.M., and N.L.B. analyzed data; B.B. wrote the first draft of the paper; B.B. and N.L.B. wrote the paper; R.K. contributed unpublished reagents/analytic tools; N.L.B. edited the paper.

This work was supported by the National Eye Institute-National Institutes of Health (Grant EY13612 to N.L.B. and Grant P30 EY012576 to U.C. Davis), a Grant-in-Aid for Scientific Research on Innovative Areas (Grant 16H06480 to R.K.) from the Ministry of Education, Culture, Sports, Science, and Technology (MEXT) of Japan, and AMED-CREST (Grant JP18gm1110002 to R.K.) from the Japan Agency for Medical Research and Development. We thank Doug Forrest for Thrb2 antibody, Brad Shibata and Paul FitzGerald for assistance with histology, Julissa-Suarez Navarro and Amy Riesenberg for technical support, the U.C. Davis Eye Development group for insightful discussions, and Anna La Torre and Joel Miesfeld for critical reading of this manuscript.

The authors declare no competing financial interests.

Correspondence should be addressed to Nadean L. Brown at nlbrown@ucdavis.edu.

https://doi.org/10.1523/JNEUROSCI.2327-19.2020

Copyright $@ 2020$ the authors cone photoreceptors specified first, while rods, bipolars and Müller glia generated mostly after birth. This diversity arises from a pool of multipotent progenitor cells (RPCs) with dynamic transcriptional profiles, during retinal development (Livesey and Cepko, 2001; Clark et al., 2019). The interplay among signaling pathways and transcription factor hierarchies produces a laminated retina that receives, interprets and relays visual input to the brain.

The Notch signaling pathway is highly conserved, and regulates both the timing of neurogenesis and progenitor cell population dynamics during mouse retinal development. At the molecular level, Notch ligand-receptor binding induces sequential proteolytic cleavages of the receptor, releasing the intracellular domain (N-ICD), which forms a nuclear protein complex with Rbpj, MAML, p300 and other proteins. This complex transcriptionally activates downstream genes, with Hes 1 a frequent target (for review, see Kovall et al., 2017). Numerous studies demonstrated that too little or too much Notch signaling pro- 
Table 1. Authentication of primary antibodies used in this study

\begin{tabular}{|c|c|c|c|c|c|c|c|c|}
\hline Antigen & Source & Host & Catalog no. (clone) & Dilution used & Application & Authentication & Antibody ID & References (PMID) \\
\hline Atoh7 & Novus & Rabbit & $\begin{array}{l}\text { NBP1-88639 } \\
\text { Lot R12065 }\end{array}$ & $1: 500$ & IF & $1,2,3,4$ & AB_11034390 & 29225067 \\
\hline Blimp1/Prdm1 & Santa Cruz & Rat & SC-47732 (6D3) & 1:100 & IF & 1,3 & AB_628168 & $\begin{array}{l}30184502 \\
30463012 \\
30850343\end{array}$ \\
\hline $\begin{array}{l}\text { Arr3 } \\
\text { Cone arrestin }\end{array}$ & EMD Millipore & Rabbit & AB15282 & $1: 1000$ & IF & 1,3 & AB_11210270 & $\begin{array}{l}26453550 \\
25798616 \\
24651551\end{array}$ \\
\hline cleaved PARP (Rodent-specific) & Cell Signaling & Rabbit & 94885 & $1: 500$ & IF & 1,3 & $A B \_2800237$ & this paper \\
\hline RFP-Biotin & Abcam & Rabbit & AB34771 & 1:1000 & IF & 1,3 & $A B \_777699$ & $\begin{array}{l}26587807 \\
28641110 \\
28817801\end{array}$ \\
\hline GFP & Aves & Chicken & GFP-1020 & 1:3000 & IF & 1,3 & AB_10000240 & $>100$ in registry \\
\hline Glutamine Synthetase & EMD Millipore & Mouse & MAB302 (GS-6) & $1: 1000$ & IF & 1,3 & $A B \_309678$ & $\begin{array}{l}26283925 \\
26527153 \\
25907681\end{array}$ \\
\hline Hes1 & Cell Signaling & Rabbit & 11988 D6P2U & $1: 500$ & IF & $1,2,3,4$ & AB_2728766 & $\begin{array}{l}29681454 \\
30059908\end{array}$ \\
\hline Hes1 & Brown lab & Rabbit & $\mathrm{N} / \mathrm{A}$ & $1: 500$ & IF & $2,3,4$ & & $\begin{array}{l}30059908 \\
28675662 \\
25100656 \\
19828801 \\
16038893\end{array}$ \\
\hline Mitf & Thermo Fisher & Mouse (lgG $\mathrm{I}_{1}$ & MS-771-P1 (C5) & $1: 100$ & IF & 1,3 & AB_141542 & this paper \\
\hline Otx2-Biotin & R\&D Systems & Goat & BAF1979 & $1: 1000$ & IF & 1,3 & AB_2157171 & $\begin{array}{l}28089909 \\
30048641\end{array}$ \\
\hline Pou4f/Brn3 * & Santa Cruz & Goat & SC 6026 & $1: 50$ & IF & 1,3 & $A B \_673441$ & $\begin{array}{l}18626943 \\
21246546 \\
21452196 \\
+12 \text { more }\end{array}$ \\
\hline Pax2 & BioLegend Covance & Rabbit & $\begin{array}{l}901001 \\
\text { PRB-276P }\end{array}$ & $1: 1000$ & IF & $1,2,3$ & $\begin{array}{l}\text { AB_2565001 } \\
\text { AB_291611 }\end{array}$ & $\begin{array}{l}20437530 \\
20737600 \\
22473852 \\
30659795\end{array}$ \\
\hline Pax6 & BioLegend Covance & Rabbit & $\begin{array}{l}901301 \\
\text { PRB-278P }\end{array}$ & $1: 1000$ & IF & $1,2,3,4$ & $\begin{array}{l}\text { AB_2565003 } \\
\text { AB_291612 }\end{array}$ & $\begin{array}{l}28132835 \\
+24 \text { more }\end{array}$ \\
\hline Pax6 & Santa Cruz & Mouse $\left(\lg G_{1}\right)$ & SC-32766 (AD2.38) & 1:50 & IF & $1,2,3$ & AB_628107 & $>40$ in Registry \\
\hline $\operatorname{Rax}$ & TaKaRa & Rabbit & M228 & $1: 1000$ & IF & 3 & & $\begin{array}{l}29117559 \\
\text { this paper }\end{array}$ \\
\hline Sox9 & Millipore & Rabbit & AB5535 & $1: 500$ & IF & 1,3 & AB2239761 & $\begin{array}{l}18626943 \\
+33 \text { others }\end{array}$ \\
\hline Thrb2 & Douglas Forrest, NIH & Rabbit & $\mathrm{N} / \mathrm{A}$ & $1: 3000$ & IF & 2,3 & & 19282790 \\
\hline Tubb3 & $\begin{array}{l}\text { BioLegend } \\
\text { Covance }\end{array}$ & Rabbit & $\begin{array}{l}802001 \\
\text { PRB-435P }\end{array}$ & $1: 1000$ & IF & 1,3 & $\begin{array}{l}\text { AB_2564645 } \\
\text { AB_291637 }\end{array}$ & $\begin{array}{l}29247817 \\
16874803 \\
+ \text { others }\end{array}$ \\
\hline Tubb3 & BioLegend & Mouse & MMS-435-P & $1: 50$ & IF & 1,3 & AB_2313773 & $\begin{array}{l}16680766 \\
16786555 \\
+160 \text { more }\end{array}$ \\
\hline Vsx2/Chx10 & Exalpha & Sheep & $\begin{array}{l}\text { X1180P } \\
\text { N-terminus }\end{array}$ & $1: 500$ & IF & 1,3 & AB_2314191 & $\begin{array}{l}19827163 \\
27565351\end{array}$ \\
\hline
\end{tabular}

Authentication methods used were as follows: 1, Antibody identification at http://antibodyregistry.org; 2, Genetic validation; 3, Comparison with known published patterns in the literature; and 4, Colabeling of tagged protein with endogenous protein.

*Discontinued.

IF, Immunofluorescence.

foundly disrupts retinal development. For example, mouse Notch 1 or Rbpj conditionally mutant eyes prematurely produce RGCs and cones, progressively lose RPCs, and display retinal rosettes composed of excess photoreceptors (Jadhav et al., 2006a,b; Yaron et al., 2006; Riesenberg et al., 2009; Zheng et al., 2009; Riesenberg and Brown, 2016).

Vertebrate HES/Hes genes are orthologues of Drosophila hairy and the Enhancer of Split complex, and encode basic helixloop-helix (bHLH) transcriptional repressors (for review, see Kageyama et al., 2008; Harima et al., 2014). Hes1 is arguably the best understood, due to its involvement in a wide array of developmental processes, and association of human HES1 mutations with cancer (for review, see Liu et al., 2015; Dhanesh et al., 2016). During eye development, all cells initially express Hes1, regardless of origin from the neural ectoderm (optic cup, stalk and RPE), surface ectoderm (lens, cornea) or surrounding mesenchyme (muscles and embryonic vasculature). During embryonic growth, Hes 1 mRNA and protein oscillate, controlled cyclically by Hes1 autorepression (Hirata et al., 2002; Jensen et al., 2003), to maintain CNS progenitor proliferation. Hes 1 is downregulated at cell 
Table 2. Secondary antibodies used in this study

\begin{tabular}{|c|c|c|c|c|}
\hline Antibody & Source & Host & Catalog no. & $\begin{array}{l}\text { Dilution } \\
\text { used }\end{array}$ \\
\hline $\begin{array}{l}\text { Anti-chicken lgY } \\
\text { Alexa Fluor } 488\end{array}$ & Thermo Fisher & Goat & A-11039 & $1: 1000$ \\
\hline $\begin{array}{l}\text { Anti-sheep lgG } \\
\text { Alexa Fluor } 594\end{array}$ & $\begin{array}{l}\text { Jackson } \\
\text { ImmunoResearch }\end{array}$ & Donkey & $713-585-147$ & $1: 500$ \\
\hline $\begin{array}{l}\text { Anti-goat lgG } \\
\text { Alexa Fluor } 594\end{array}$ & Thermo Fisher & Donkey & A11058 & $1: 500$ \\
\hline $\begin{array}{l}\text { Anti-rabbit lgG } \\
\text { Alexa Fluor } 594\end{array}$ & Thermo Fisher & Goat & A11037 & $1: 500$ \\
\hline $\begin{array}{l}\text { Anti-mouse } \lg G(\mathrm{H}+\mathrm{L}) \\
\text { Alexa Fluor } 647\end{array}$ & Thermo Fisher & Goat & A21236 & $1: 200$ \\
\hline $\begin{array}{l}\text { Anti-mouse } \lg _{1} \\
\text { Alexa Fluor } 647\end{array}$ & Thermo Fisher & Goat & A212540 & $1: 200$ \\
\hline $\begin{array}{l}\text { Anti-rat lgG } \\
\text { Alexa Fluor } 594\end{array}$ & $\begin{array}{l}\text { Jackson } \\
\text { ImmunoResearch }\end{array}$ & Donkey & $712-586-153$ & $1: 500$ \\
\hline $\begin{array}{l}\text { Streptavidin } \\
\text { AlexaFluor } 594\end{array}$ & $\begin{array}{l}\text { Jackson } \\
\text { ImmunoResearch }\end{array}$ & Not applicable & S32356 & 1:1000 \\
\hline DAPI $1 \mathrm{mg} / \mathrm{ml}$ & Sigma-Aldrich & Not applicable & & $1: 500$ \\
\hline
\end{tabular}

RPCs exhibit the "salt and pepper" pattern characteristic of oscillatory behavior.

Previous explorations of Hes1 used a germline mutant mouse, ex vivo retinal culture and viral misexpression (Tomita et al., 1996; Furukawa et al., 2000; Takatsuka et al., 2004; Lee et al., 2005). These studies highlighted Notch-dependent Hes1 activities, including regulating the ratio of proliferating to differentiating RGCs, the embryonic apical outer limiting membrane and retinal lamination. Without Hes 1 , apical $N$-Cadherin in RPCs is discontinuous, and RGCs occupy the subretinal space, leading to cellular rosettes, a manifestation of abnormal lamination (Takatsuka et al., 2004). Hes 1 is not solely regulated by the Notch pathway, since it also depends on Hedgehog (Hh) signaling (Solecki et al., 2001; Wall et al., 2009). It remains unknown how Hes1 has two simultaneous expression modes, and how it responds to particular signaling inputs. To unravel these questions, we removed Hes1 during retinal development, using two Cre transgenic mouse lines, Chx10-Cre and Rax-Cre, and compared these mutant phenotypes across eye development. The Chx10-Cre driver deletes genes from E10.5 exclusively within RPCs. Although this driver has mosaic activity, it is relatively low before E13.5. Rax-Cre initiates recombination at least one day earlier, without mosaicism, and acts in the ventral thalamus/hypothalamus, optic vesicle, cup and stalk, RPE, ONH and RPCs. (Klimova et al., 2013; Klimova and Kozmik, 2014; Pak et al., 2014).

The onset of neurogenic phenotypes in both conditional mutants phenocopy each other, and germline mutants (Tomita et al., 1996; Takatsuka et al., 2004; Lee et al., 2005). We discovered that both conditional mutants produce significantly fewer cone photoreceptors that persists into adulthood. This is in stark contrast to an overproduction of cones in Notch1, Rbpj, Dll4 or Dll1;Dll4 retinal mutants, suggesting Hes1 does not directly repress cone-specific gene expression, but acts in a more complex manner. Both adult Hes 1 Cre mutants have excess bipolar neurons; but only Rax-Cre;Hes1 mutants have abnormally positioned Müller glial cells. Only Rax-Cre mutants revealed a novel role for Hes1 in maintaining the optic cup-stalk boundary, where Pax6 + neural retina expanded at the expense of Pax $2+$ optic stalk, resulting in a failure to close the optic fissure. Our data significantly extend the known roles for Hes1 during vertebrate eye development, and implicate cycle exit and differentiation. Importantly, Hes1 also exhibits high, sustained expression in domains that are physical boundaries between CNS progenitor cell compartments (for review, see Kageyama et al., 2007; Imayoshi et al., 2013; Imayoshi and Kageyama, 2014). One region is the brain isthmus, where cells expressing high Hes 1 proliferate at a slower rate, and differentiate into glia (Baek et al., 2006). In the embryonic eye, at the juncture of the optic cup and optic stalk, is a ring of cells termed the optic nerve head $(\mathrm{ONH})$, which is a boundary between neural retina and optic stalk glia (Tao and Zhang, 2014). We found that $\mathrm{ONH}$ cells express Hes1 at high, sustained levels, whereas adjacent human HES1 mutations as candidates for optic nerve coloboma.

\section{Materials and Methods} $\left(H e s 1^{\text {tm1Kag }}\right)$ maintained on both $\mathrm{CD}-1$ and $\mathrm{C} 57 \mathrm{BL} / 6 \mathrm{~J}$ backgrounds (Imayoshi et al., 2008); Hes $1^{\mathrm{KO} /+}\left(\right.$ Hes $\left.1^{\mathrm{tm} 1 \mathrm{Fgu}}\right)$ or Hes $1^{\mathrm{KO} /+} ;$ Atoh $7^{\mathrm{Tg}}$ GFP/+ mice (Ishibashi et al., 1995; Hutcheson et al., 2005) maintained on a CD-1 background; Chx10-Cre BAC transgenic line [ $\mathrm{Tg}$ (Chx10-EGFP/ cre;-ALPP)2Clc; JAX stock number 005105] maintained on a CD-1 background (Rowan and Cepko, 2004); Ai9 Cre lineage tracer

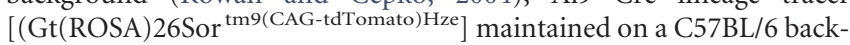

Animals. Mouse strains used in this study were a Hes $1^{\text {CKO }}$ allele 


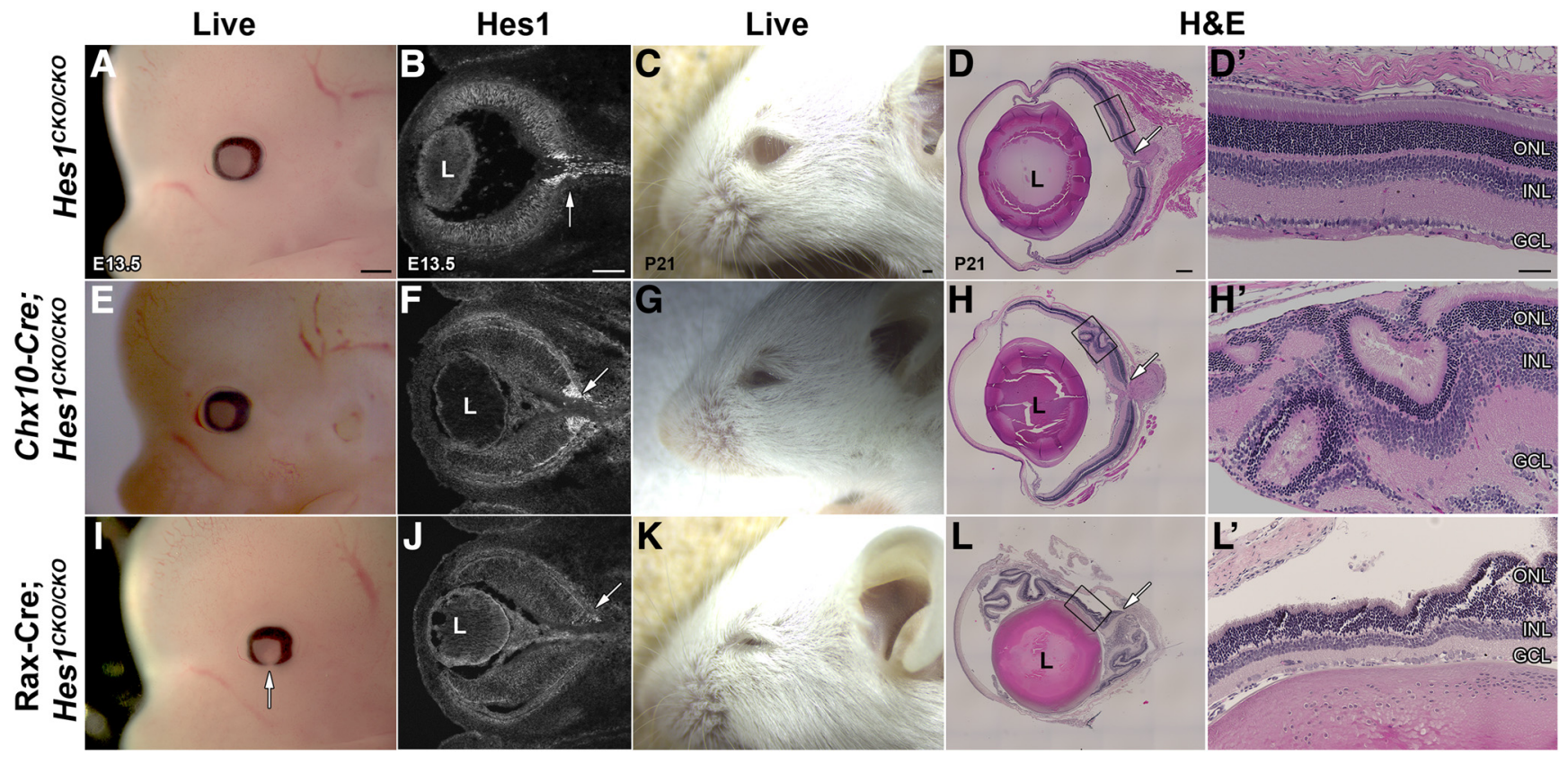

Figure 2. Hes1 conditionally mutant ocular defects. $\boldsymbol{A}, \boldsymbol{E}$, $\boldsymbol{I}$, Lateral views of $\mathrm{E} 13.5$ live embryos. Chx10-Cre;Hes $7^{\mathrm{CK} 0 / \mathrm{CK} 0}$ eyes $(\boldsymbol{E})$ are indistinguishable from control littermates $(\boldsymbol{A})$. However Rax-Cre; Hes $7^{\mathrm{CKO} / \mathrm{CKO} 0}$ eyes have fully penetrant colobomas (arrow in I). $\boldsymbol{B}, \boldsymbol{F}, \boldsymbol{J}$, Anti-Hes 1 labeling of E13.5 cryosections indicates the identical loss of low, nonuniform expression from the retina of both Cre-mutants. However, Chx10-Cre;Hes $7^{\mathrm{CKO} / \mathrm{CKO}}$ eyes retain high, sustained Hes1 expression in the 0NH (arrows in each panel). Rax-Cre; Hes $7^{\mathrm{CKO} / \mathrm{KK} 0}$ uniquely exhibited an abnormal elongated shape to the retina $(\boldsymbol{J}) . \boldsymbol{C}, \boldsymbol{G}, \boldsymbol{K}$, Gross examination of P21 eyes suggests microphthalmia in Chx10-Cre;Hes $7^{\mathrm{CK} 0 / \mathrm{CKO}}(\boldsymbol{G})$ and Rax-Cre;Hes $7^{\mathrm{CK} 0 / \mathrm{CK} 0}(\boldsymbol{K})$ mutants. $\boldsymbol{D}, \boldsymbol{H}, \boldsymbol{L}$, However, H\&E-stained P21 sections at the level of the optic nerve support smaller eyes only for Rax-Cre;Hes 7 CKo/CKO . Both mutants have lamination defects and retinal rosettes $(\boldsymbol{H})$, along with severe thinning of retinal layers $(\boldsymbol{L}) . \boldsymbol{D}^{\prime}, \boldsymbol{H}^{\prime}$, and $\boldsymbol{L}^{\prime}$ are higher magnifications of boxed areas in $\boldsymbol{D}, \boldsymbol{H}$, and $\boldsymbol{L}$, respectively. L, lens; $0 \mathrm{NL}$, outer nuclear layer; INL, inner nuclear layer; $G C L$, ganglion cell layer. Scale bars: $50 \mu \mathrm{m}$ in $\boldsymbol{B}, \boldsymbol{D}$, and $\boldsymbol{D}^{\prime}$ and $500 \mu \mathrm{m}$ in $\boldsymbol{A}$ and $\boldsymbol{C} . n=3$ biologic replicates per age and genotype were evaluated.

ground (Madisen et al., 2010); and Rax-Cre BAC transgenic line $\operatorname{Tg}($ Raxcre) NL44Gsat/Mmucd created by the GENSAT project, cryobanked at MMRRC U.C. Davis (stock no. 034748-UCD) and maintained on a CD-1 background. PCR genotyping was performed as described previously (Ishibashi et al., 1995; Rowan and Cepko, 2004; Hutcheson et al., 2005; Imayoshi et al., 2008; Madisen et al., 2010). Conditional mutant breeding schemes mated one Cre $\mathrm{Tg} /+$ mouse to another homozygous for the Hes1 conditional allele to create Cre;Hes $1^{\mathrm{CKO} /+}$ mice, used in timed matings to Hes $1^{\mathrm{CKO} / \mathrm{CKO}}$ mice. The date of a vaginal plug was assigned the age of E0.5. All mice were housed and cared for in accordance with guidelines provided by the National Institutes of Health, Bethesda, MD, and the Association for Research in Vision and Ophthalmology, and conducted with approval and oversight from the U.C. Davis Institutional Animal Care and Use Committees.

Histology and immunohistochemistry. For histology, P0 and P21 eyes were dissected and fixed in $4 \%$ paraformaldehyde overnight at $4{ }^{\circ} \mathrm{C}$ and underwent standard processing for paraffin-embedding, then $4 \mu \mathrm{m} \mathrm{sec}$ tions were generated and H\&E stained. For immunohistochemistry, embryonic tissue was fixed in $4 \%$ paraformaldehyde/PBS for $1 \mathrm{~h}$ on ice, processed by stepwise sucrose/PBS incubation ranging from 5 to $15 \%$, and embedded in Tissue-Tek OCT, then $10 \mu \mathrm{m}$ frozen sections were generated and antibody labeled as in (Mastick and Andrews, 2001). Details about the primary and secondary antibodies used are provided in Tables 1 and 2. Nuclei were counterstained with DAPI.

EdU incorporation. EdU pulse labeling was performed by injecting EdU in pregnant dams carrying E13.5 litters $(12 \mu \mathrm{g} / \mathrm{g}$ body weight of 1 $\mathrm{mg} / \mathrm{ml} \mathrm{EdU} \mathrm{in} 0.15 \mathrm{M} \mathrm{NaCl}$ ) and harvesting embryos after $1.5 \mathrm{~h}$. EdU was detected using Click-iT EdU Cell Proliferation Kit for Imaging (Thermo Fisher Scientific, catalog \#C10339).

Microscopy and statistical analysis. Digital TIF images of living embryos with tdTomato expression were captured on a Leica MZ12 dissecting microscope, equipped with a UV light source, Spot B\&W and color cameras and Spot software (v5.2). TIF images of adult mouse heads were imaged using a Leica MZ8 dissecting microscope, DFC290 HD camera and Leica LAS V4.2 software. Histologic sections were imaged with a Zeiss Axio Imager M.2 microscope, color camera and Zen software (v2.6). Antibody labeled cryosections were imaged using a Leica DM5500 microscope, equipped with a SPEII solid state confocal and processed using Leica LASX (v.3), ImageJ software, and Adobe Photoshop (CS5) software programs. All images were equivalently adjusted for brightness, contrast, and pseudo-coloring. For embryonic sections, $\geq 3$ individuals were analyzed, using at least 2 sections per individual. For cell counting, three or more animals were analyzed per genotype and age, with $\geq 2$ sections per control or mutant littermate. Sections were judged to be of equivalent depth by presence of or proximity to the optic nerve. Marker+ cells in tissue sections were counted using the count tool in Adobe Photoshop CS5 and statistical analyses performed using Prism software (GraphPad v7) and Excel (v16.16.11), with $p$-values determined with one-way ANOVA with Dunnett's test.

\section{Results}

At the end of gastrulation, the eye field is specified, bisected laterally and each optic vesicle evaginates from the ventral diencephalon. Multiple signaling pathways regionalize the growing optic vesicles, delineating the neural retina (NR), retinal pigment epithelium (RPE) and optic stalk (OS). This process also produces a unique cuff of cells, called the optic nerve head (ONH), which serves as a physical and molecular boundary between the neural retina and glial optic stalk (for review, see Tao and Zhang, 2014). Retinal progenitor cells (RPCs) exhibit nonuniform Hes1 expression, consistent with its established role in promoting growth and suppressing neurogenesis. Using a validated antibody (Lee et al., 2005), we found that beginning around E12.5, ONH cells express high levels of Hes1 protein, compared with the adjacent retina, RPE and lens epithelial domains. These expression differences are easily seen at E13.5 and E16.5 (Fig. $1 A, B$ ). In cross section, the $\mathrm{ONH}$ is triangular, defined morphologically by the opening that allows RGC axons to exit into the optic stalk lumen, but molecularly where it is contiguous with the NR (Fig. 1B). The high Hes1 domain corresponds to that of Pax2, previously shown 
to be essential for $\mathrm{ONH}$ and OS development (see Figs. $1 A, F$, $3 A, D$ ) (Torres et al., 1996; Otteson et al., 1998; Schwarz et al., 2000).

Chx10-Cre and Rax-Cre driver activities overlap in RPCs but not in the $\mathrm{ONH}$

To tease apart Hes1 functions in the developing retina versus ONH/optic stalk, we used two conditional deletion strategies. First, a Chx10-Cre BAC transgenic driver was used for consistency with previous retinal analyses of Notch1 and Rbpj (Jadhav et al., 2006a,b; Riesenberg et al., 2009). Because Chx10/Vsx2 expression is quickly confined to RPCs once the optic cup forms, we also searched for another Cre transgenic line that would remove Hes 1 at earlier stages, and within the forming ONH/OS. The Rax/Rx transcription factor is one of the earliest genes to demarcate the eye field (Furukawa et al., 1997; Mathers et al., 1997). Previously the GENSAT/MMRRC project created a Rax-Cre BAC transgenic mouse by recombineering a Cre expression cassette into the identical BAC clone used by Sasai and colleagues for a widely used Rax-GFP transgenic mouse cell line (Wataya et al., 2008). So, we acquired this MMRRC Rax-Cre line, and compared its activity to Chx10-Cre (Fig. 1). Although an ONH-specific Cre driver would be ideal for our experiments, an exhaustive search identified only one possible tool, a BAC transgenic Pax2-Cre mouse containing $120 \mathrm{~kb}$ of the mouse Pax2 locus (Ohyama and Groves, 2004) that unfortunately lacks embryonic eye enhancer(s).

First, we compared the spatiotemporal expression of a Cre-induced tdTomato reporter (Ai9-Rosa26-CAG-loxP-STOPloxP-tdTomato) in timed matings with each Cre driver (Fig. $1 C$ $J)$. For Chx10-Cre, we did not detect any tdTomato expression in the E9.5 optic vesicles (Fig. $1 C$, arrow), but readily saw expression from E10.5 onwards (Fig. 1D, arrow), in agreement with previous studies (Rowan and Cepko, 2004). At E13.5, anti-DsRed labeling of horizontal sections highlighted tdTomato expression within the NR, and lineage-traced nascent RGC axons within the OS (Fig. 1E,F). To confirm retinal-specificity, we colabeled E13.5 Chx10-Cre cryosections with anti-GFP and anti-Pax2, further demonstrating that the Cre-GFP fusion protein is almost entirely absent from Pax2+ ONH and OS cells (Fig. $1 F-F^{\prime \prime}$ ).

By contrast, Rax-Cre;Ai9 embryos have tdTomato expression in the E9.5 optic vesicle and developing forebrain (Fig. 1G) that is highly visible at E11.5 (Fig. $1 H$, arrow). The reporter expression within the telencephalon and diencephalon (data not shown), reflects endogenous Rax expression domains (Furukawa et al., 1997; Mathers et al., 1997; Asbreuk et al., 2002). At E13.5 antiDsRed labeling demonstrated the expected NR, RPE, ONH and OS domains, since these tissues derive from the optic vesicle (Fig. 1I). In E13.5 DsRed/Pax2 colabeled sections all Pax2+ ONH cells are present in the Rax-Cre lineage (Fig. $\left.1 J-J^{\prime \prime}\right)$. Where Chx10Cre and Rax-Cre activities overlap in the NR, nonuniform Hes 1 activity will be removed from RPCs, thereby inducing neurogenic phenotypes akin to those previously described for the Notch pathway (Jadhav et al., 2006a,b; Riesenberg et al., 2009). However, Rax-Cre is predicted to also remove high, sustained Hes 1 expression, allowing us to test the requirements for Hes1 in the $\mathrm{ONH}$ and/or OS.

Hes1 conditional mutants have retinal lamination defects and persistent coloboma

We, and others, previously showed that Hes1 germline mutant embryos are microphthalmic and die before birth, from multiple organ system defects (Tomita et al., 1996; Lee et al., 2005; Kameda et al., 2011). To demonstrate that these conditional mutants are adult viable,
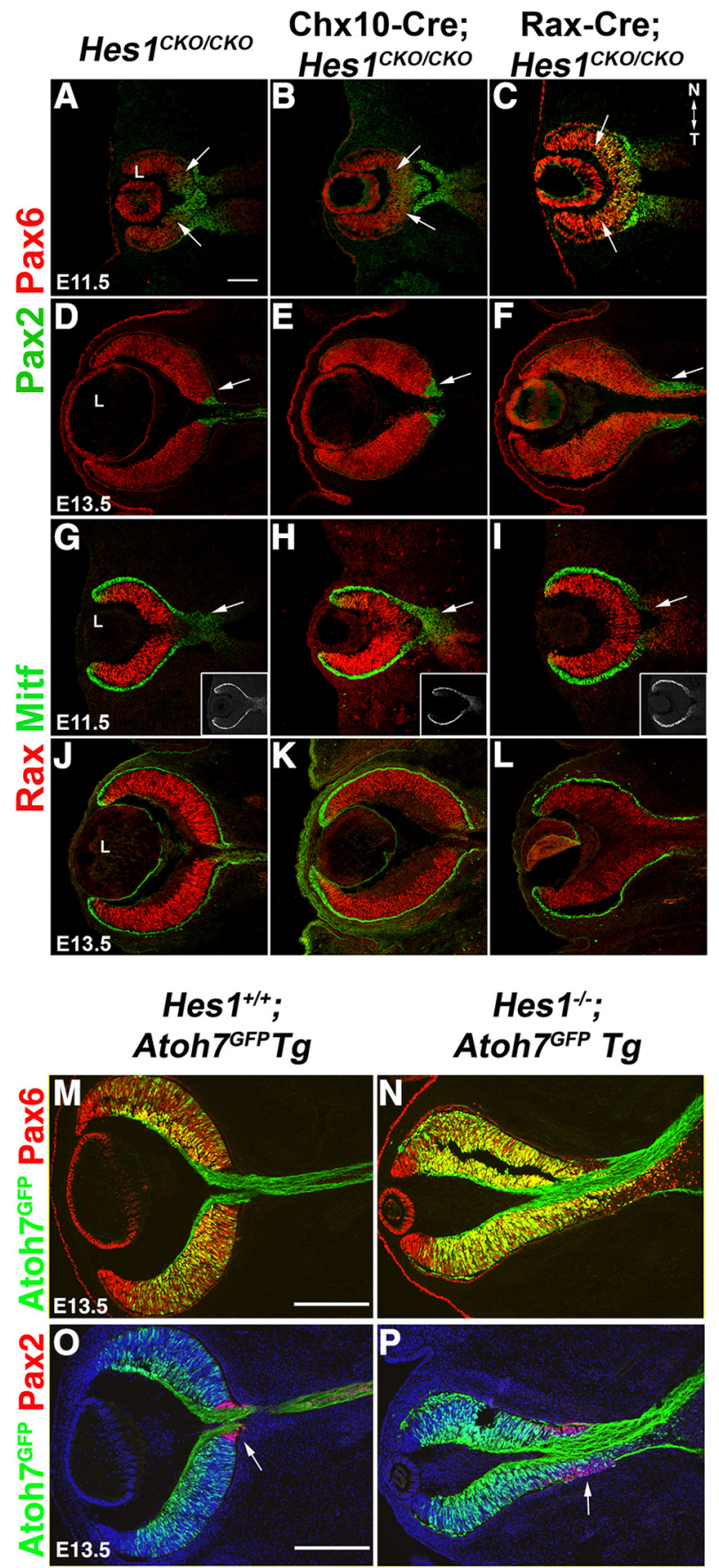

Figure 3. Specific alteration of the optic cup-stalk boundary in Rax-Cre;Hes $7^{\text {CKo/CK0 }}$ and Hes $1^{-1-}$ embryos. Immunolabeling of E11.5 and E13.5 horizontal sections containing retina, ONH and optic stalk. $\boldsymbol{A}-\boldsymbol{F}$, Pax6-Pax2 colabeling. These transcription factors are initially coexpressed, but by E13.5, abut each another in nonoverlapping domains, thereby highlighting the $\mathrm{NR} / \mathrm{OC}-\mathrm{ONH}$ boundary (arrow in $\boldsymbol{D}$ ). Although the abutting expression domains arise in both Chx $10-C r e ; H e s 7^{\mathrm{CKO} / \mathrm{CKO} O}(\boldsymbol{B}, \boldsymbol{E})$ and Rax-Cre;Hes $7{ }^{\mathrm{CKO} / \mathrm{CKO}}(\boldsymbol{C}, \boldsymbol{F})$ eyes, the position of the boundary is more proximal and highlights an expansion of the retinal territory $(\boldsymbol{F})$. This defect is phenocopied in Hes 1 germline mutants $(\boldsymbol{N}, \boldsymbol{P}) . \mathbf{G}-\boldsymbol{L}$, Rax-Mitf colabeling for the retinal-RPE boundary in nearby sections. In both conditional mutants, these tissues are essentially normal, although Rax-Cre;Hes $7^{\mathrm{CKO} / \mathrm{CKO} 0}$ eyes always displayed complete suppression of Mitf in the E11.5 ONH/OS (arrows in G-I and insets of Mitf expression). AtE13.5, proximal expansion of RPE matched that of the neural retina. $\mathbf{M}, \mathbf{0}$, Normal Pax6, Pax2 (arrow in $\mathbf{0}$ ) and Atoh7-GFP transgene expression domains. $\boldsymbol{N}, \boldsymbol{P}$, In Hes 1 germline mutants, inappropriate proximal expansion of Pax6+ optic cup cells, accompanied by a proximal shift of the Pax2 ONH domain, which is also misshapen (arrow in $\boldsymbol{P}$ ). Atoh7-GFP expression highlights a previously described RGC neurogenic phenotype. L, lens. Scale bars in $A, M, 0,50 \mu \mathrm{m} . n>3$ biologic replicates per age and genotype were analyzed. 

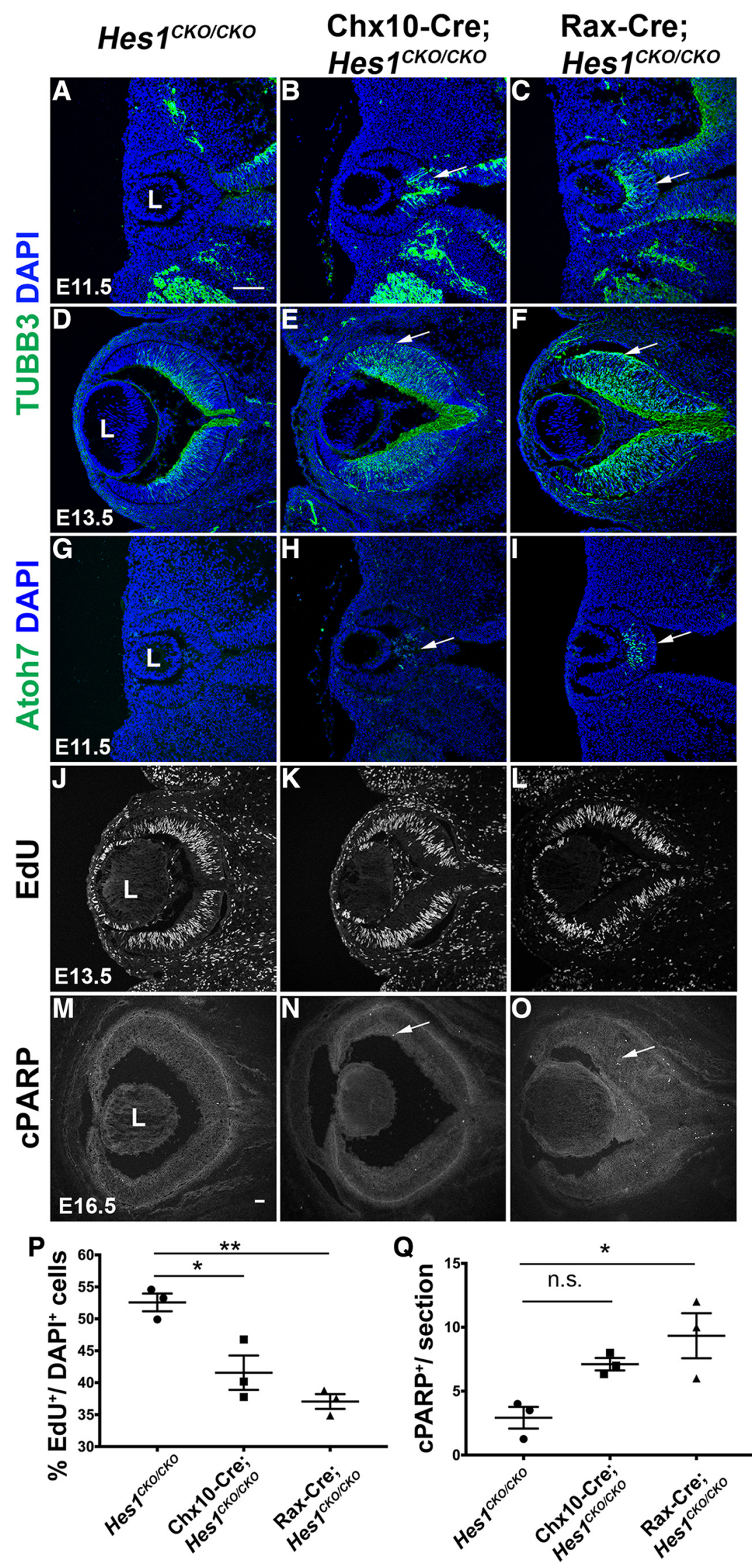

Figure 4. Hes 1 conditional mutants have expected neurogenic and RPC pool depletion phenotypes. $\boldsymbol{A}-\boldsymbol{F}$, TUBB3 labeling of nascent retinal neurons at E11.5 and E13.5. Premature neurogenesis is in progress at E11, and by E13.5, there is a dramatic increase of Tubb3 + cells in both Chx10-Cre;Hes $1^{\text {CKO/CKO }}$ and Rax-Cre;Hes $1^{\text {CKO/CKO }}$ eyes. Some ectopic neurons are improperly positioned in we bred mice homozygous for the Hes 1 floxed allele ( $\left.\mathrm{Hes} 1^{\mathrm{CKO} / \mathrm{CKO}}\right)$ to Chx10Cre;Hesl ${ }^{\mathrm{CKO} /+}$ or Rax-Cre;Hesl ${ }^{\mathrm{CKO} /+}$ mice (Fig. 2). Conditionally mutant adults were produced at an expected 25\% Mendelian ratio, with completely penetrant ocular deformities (Fig. 2) ( $n=7$ mutants Chx10-Cre; 3 mutants Rax-Cre). Throughout this study, controls are $\mathrm{Hes} 1^{\mathrm{CKO} / \mathrm{CKO}}$ littermates, and Cre; Hesl heterozygotes $\left(\mathrm{Hes}^{\mathrm{CKO} /+}\right)$ displayed no obvious phenotypes.

Then, we analyzed the morphology of control and mutant eyes during embryogenesis (Fig. 2A,E,I). E13.5 Chx10-Cre; $\mathrm{Hes}{ }^{\mathrm{CKO} / \mathrm{CKO}}$ eyes showed no apparent differences compared with control retinas (Fig. 2E). However, E13.5 Rax-Cre; Hes $1^{\text {CKO/CKO }}$ eyes exhibited coloboma, a failure of optic fissure closure (Fig. 2I, arrow). The optic fissure is a transient structure that normally closes by E12.5. However, at all ages examined, Rax-Cre; $\mathrm{Hes} 1^{\mathrm{CKO} / \mathrm{CKO}}$ animals had incomplete fissure closure $(100 \%, n>22)$, thus we conclude this defect is not simply a developmental delay. Next, we confirmed the loss of Hes1 nuclear protein by immunohistochemistry (Fig. $2 B, F, J$ ). In Chx10-Cre; Hes $1^{\mathrm{CKO} / \mathrm{CKO}}$ retinas, low, nonuniform expression in RPCs was absent, although high, sustained expression persisted in the adjacent $\mathrm{ONH}$ and $\mathrm{OS}$ (Fig. 2F, arrow). In Rax-Cre;Hes 1 CKO/CKO retinas nearly all expression domains were missing (Fig. 2J), and the optic cup had a fully penetrant, elongated shape.

Next we surveyed the adult eyes from Hes1 conditional mutants. Both Cre mutants grossly appear to have bilateral microphthalmia (Fig. $2 G, K$ ), however smaller eye size was only evident in P21 Rax-Cre;Hes $1^{\mathrm{CKO} / \mathrm{CKO}}$ ocular sections (Fig. 2L). Both Chx10-Cre; Hes $1^{\mathrm{CKO} /}$ CKO and Rax-Cre;Hes $1^{\text {CKO/CKO }}$ retinas had lamination defects that included retinal rosettes (Fig. 2D, $D^{\prime}, H, H^{\prime}, L, L^{\prime}$ ). Our data corroborate previous descriptions of Hes1 germline mutants, and allow

\section{$\leftarrow$}

the outer retina and/or have aberrant trajectories (arrows in $E$ and $\boldsymbol{F}$ ). $\mathbf{G}-\boldsymbol{I}$, Precocious Atoh7 expression at E11 (arrows in $\boldsymbol{H}$ I), also phenocopies Hes 1 germline mutants (Takatsuka et al., 2004; Lee et al., 2005). J-L, $\boldsymbol{P}$, E13.5 sections containing the ON from embryos pulse-labeled with EdU 90 min before dissection. $\boldsymbol{M}-\mathbf{0}, \mathbf{Q}$, Anti-cPARP labeling of nearby sections to assess apoptosis. $\boldsymbol{P}$, Statistically significant loss of EdU ${ }^{+} \mathrm{RPCS}$ in both mutants. $\mathbf{Q}, \mathrm{CPARP}^{+}$cells (arrows in $\boldsymbol{N}, \mathbf{0}$ ) were increased, with statistical significance for Rax-Cre; Hes 7 CKO/CKO eyes. Both graphs display individual data points, the mean and SEM; $n$.s., not significant; ${ }^{*} p<0.05 ;{ }^{* *} p<0.01$. L, lens. Scale bars in $A$ and $M, 50 \mu$ m. $n=3$ biologic replicates ( 2 or more sections/replicate) per age and genotype were quantified. 


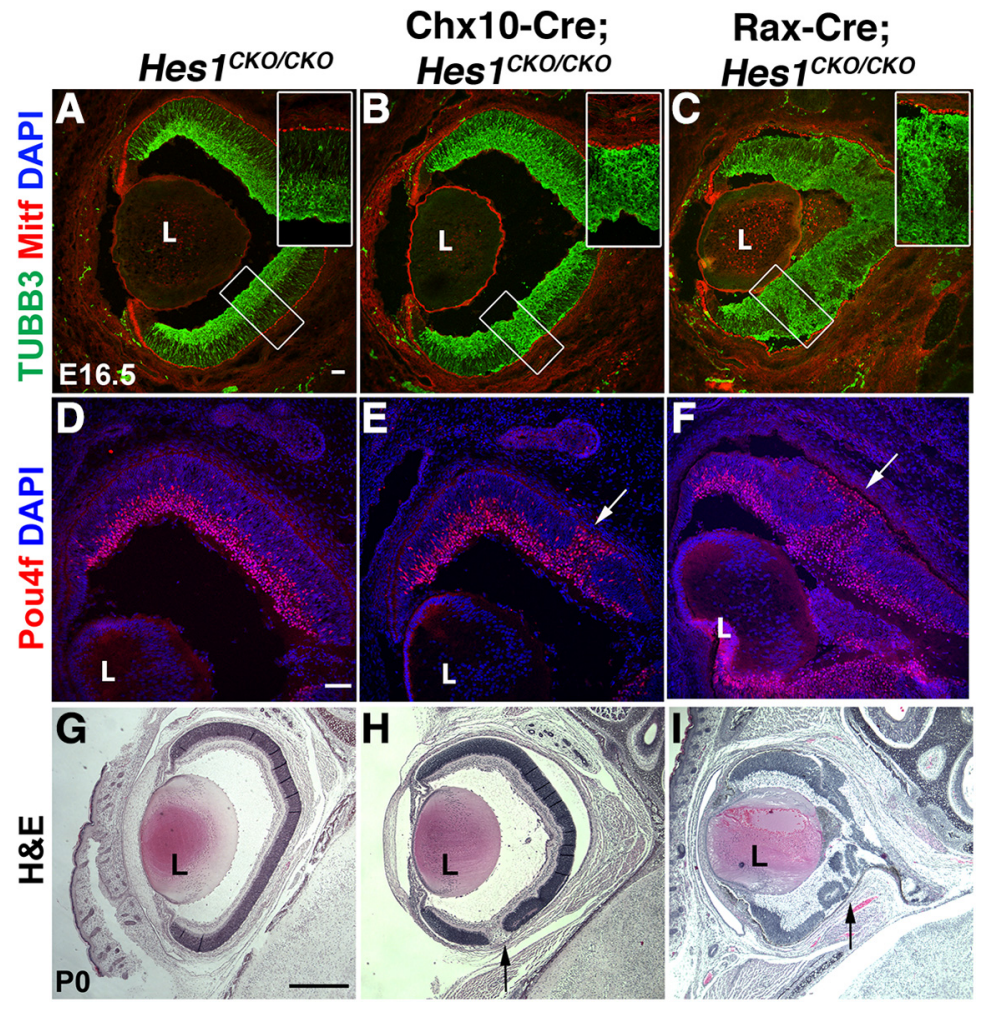

Figure 5. RGC patterning defects in Hes 1 retinal mutants. $\boldsymbol{A}-\boldsymbol{C}$, Colabeling for Tubb3 and Mitf highlights patches of abnormal neuronal processes inappropriately on the apical side of the retina (inset boxes). $\boldsymbol{D}-\boldsymbol{F}$, Pou4f nuclear expression in differentiated RGCS better highlights RGC cell body mispatterning in the patches (arrows in $\boldsymbol{E}, \boldsymbol{F}$ ). Previous examination of Hes 1 germline mutants showed an early loss of the OLM, a boundary that also confers apical-basal positional information to RPCs (Takatsuka et al., 2004). $G-I, P 0 H \& E$ sections with retinal rosettes and breaks in the outer retina (arrows in $H, I$ ). L, lens. Scale bars: $A$ and $D, 50 \mu \mathrm{m}$ with insets $400 \times$ magnified; $\mathbf{G}, 500 \mu \mathrm{m} . n=3$ biologic replicates per age and genotype analyzed.

us examination of Hes 1 functions at every stage of retinogenesis. Importantly, Rax-Cre;Hes $1^{\mathrm{CKO} / \mathrm{CKO}}$ phenotypes most closely matched those of Hes1 germline mutants, and uncovered two significant defects: persistent coloboma and early changes in optic cup shape.

\section{Hes1 maintenance of the optic cup-stalk boundary}

The cells situated between the optic cup and stalk, represent a neural-glial cell tissue boundary that is defined molecularly by the mutually suppressive activities of Pax2 and Pax6 (Schwarz et al., 2000). Although these factors are initially coexpressed in the E9.5 optic vesicle, they are simultaneously downregulated in adjacent tissues: Pax2 in optic cup, and Pax6 in the OS. This establishes a boundary via mutually exclusive expression domains. The clearest demonstration that the $\mathrm{ONH}$ is a boundary came from Pax2 germline mutants, in which Pax6 NR expression expands proximally, along the optic stalk (Torres et al., 1996; Schwarz et al., 2000). At E11.5, we saw that the Pax6 and Pax2 domains were actively separating, but were still coexpressed in the forming $\mathrm{ONH}$ (Fig. 3A, arrows). E11.5 Chx10-Cre;Hes $1^{\mathrm{CKO} / \mathrm{CKO}}$ and Rax-Cre;Hes $1^{\mathrm{CKO} / \mathrm{CKO}}$ optic cups showed essentially normal Pax6 and Pax2 domains, although the area of coexpression appeared broader in some Rax-Cre mutants (Fig. 3B,C, arrows). At E13.5, in both wild-type and Chx10-Cre; Hes $1{ }^{\mathrm{CKO} / \mathrm{CKO}}$ optic cups there was complete separation of Pax6 NR and Pax2 ONH/OS domains (Fig. 3D,E). However, in Rax-Cre; Hes $1{ }^{\mathrm{CKO} / \mathrm{CKO}}$ eyes the Pax6 NR domain was clearly expanded, but the Pax2+ ONH cells were also misplaced proximally (Fig. 3F, arrow). This defect is identical to Hes 1 germline mutants (Fig. $3 M-P$ ), where all Hes1 expression is lacking. Because Pax6 and Pax2 do- mains can separate without Hes1, we conclude that its role is to maintain the $\mathrm{ONH}$ boundary.

Next, we investigated whether loss of Hes1 also affected NR and RPE separation, particularly at the ciliary margin, by colabeling with specific antibodies for Rax (NR) and Mitf (RPE). At both ages, control and Chx10-Cre;Hes $1^{\mathrm{CKO} / \mathrm{CKO}}$ optic cups had indistinguishable expression of these markers (Fig. $3 G, H, J, K$ ). Although at E11.5 Mitf is normally present in both the RPE and OS, later it becomes restricted to the RPE (Fig. 3G,H, arrows and insets). In contrast, we never saw Mitf expression within the E11.5 Rax-Cre; Hes ${ }^{\mathrm{CKO} / \mathrm{CKO}}$ OS (Fig. 3I, inset), suggesting these cells may be changing their fate to retinal. At E13.5, Rax-Cre;Hes $1^{\mathrm{CKO} / \mathrm{CKO}}$ eyes displayed an inappropriate expansion of Rax and Mitf into the OS (cf. Fig. $3 L$ and $J, K$ ), as shown for Pax6 (Fig. 3F). We conclude that the NR, RPE and ciliary margin territory formation is unaffected in both conditional mutants. But, in Rax-Cre; $\mathrm{Hes} 1^{\mathrm{CKO} / \mathrm{CKO}}$ eyes, lacking both low, nonuniform and high, sustained Hes1 expression, a profound requirement for Hes1 in ONH cells to sustain this boundary was revealed.

\section{Hes1 in embryonic retinal \\ progenitor cells}

Multiple analyses of Hes 1 germline mutants describe precocious and rapid neurogenesis of Tubb3+ neurons that impact the remaining progenitor cell pool (Ishibashi et al., 1995; Nakamura et al., 2000; Ohtsuka et al., 2001; Takatsuka et al., 2004). These mutants also display patchy deformity to the outer limiting membrane, and contain excess retinal neurons in the subretinal space (Takatsuka et al., 2004). Although the excess Tubb3 + neurons are highly likely to be RGCs, this was not formally shown. First, we labeled E11.5 and E13.5 control, Chx10-Cre;Hes $1^{\mathrm{CKO} / \mathrm{CKO}}$ and Rax-Cre;Hes $1^{\mathrm{CKO} / \mathrm{CKO}}$ sections with Tubb3 to verify that both conditional mutants contained ectopic Tubb3 + optic cup cells (Fig. 4A-F, arrows). At the older age, ectopic Tubb3 expression was quite expanded apically, which was more prominent in Rax-Cre;Hes $1{ }^{\mathrm{CKO} / \mathrm{CKO}}$ eyes. Some ectopic Tubb3 + neurons and their processes could be seen in the subretinal space (Fig. 4E, F, and see Fig. 5, arrows). The proneural bHLH factor Atoh7 normally initiates expression in the E11.5 central optic cup (Brown et al., 1998) (Miesfeld et al., 2018). Previously we reported precocious Atoh7 mRNA expression at E9.5, but without an increase in expression levels in Hes1 germline mutants (Lee et al., 2005). In the central optic cup of both conditional mutants, we observed ectopic Atoh7+ cells (Fig. $4 H, I$, arrows), whereas control littermates had not yet initiated expression (Fig. 4G).

Hes1 has well described functions in influencing cell cycle dynamics (Uriu, 2016). All Hes1 mutants contain excess neurons, which negatively feedbacks on growth. Therefore, we quantified the pool of proliferating RPCs by EdU pulse-labeling timed pregnant mice. We observed significant reduction in the number of $\mathrm{EdU}+\mathrm{RPCs}$ in both Chx10-Cre;Hes $1^{\mathrm{CKO} / \mathrm{CKO}}$ and Rax-Cre; 


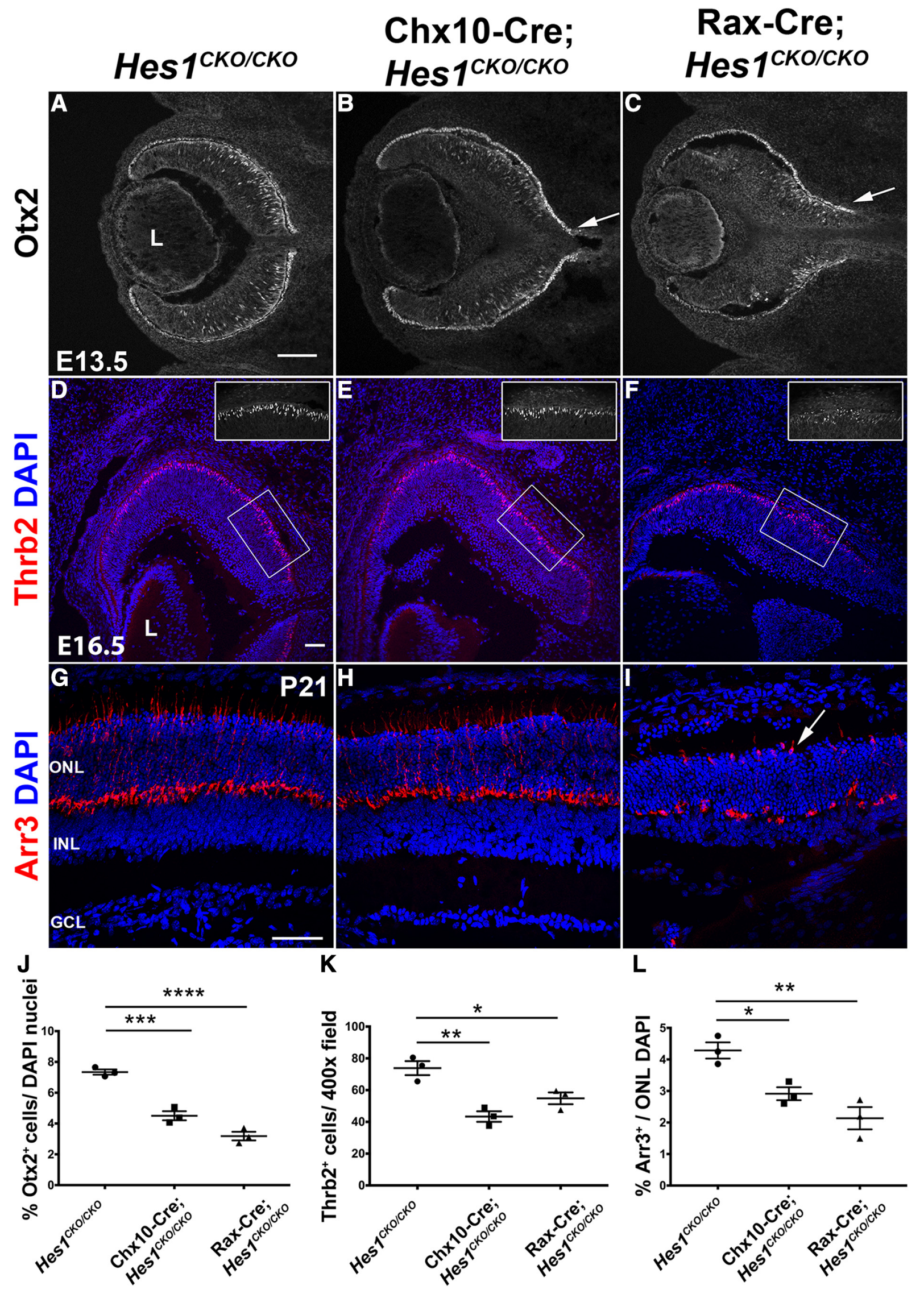

Figure 6. Loss of Hes 1 results in failed cone photoreceptor formation. $\boldsymbol{A}-\boldsymbol{C}, \boldsymbol{J}, \mathrm{RPCS}$ competent to develop into photoreceptor or bipolar neurons express the 0 tx 2 homeobox protein, as well as early-stage E9-E13 RPE cells (Nishida et al., 2003; Fossat et al., 2007). The percentage of 0tx2 + retinal cells was quantified (J), using total DAPI + nuclei to normalize for the elongated retinal shape of Hes1 mutants (arrows in $\boldsymbol{B}, \mathbf{C}$. D-F, $\boldsymbol{K}$, Anti-Thrb2 labeling (a cone-specific factor) of E16.5 sections also showed a statistically significant loss of cones in the (Figure legend continues.) 
Hes $1^{\mathrm{CKO} / \mathrm{CKO}}$ retinas compared with control littermates (Fig. $4 \mathrm{~J}-$ $L, P)$. To determine which defects contribute to microphthalmia in Hes 1 mutants, we also quantified apoptotic cells at E16.5 by labeling with anti-cPARP (Fig. 4M-O,Q). There was an increase in the number of cPARP + cells in both Chx10-Cre;Hes $1{ }^{\mathrm{CKO} / \mathrm{CKO}}$ and Rax-Cre;Hes ${ }^{\mathrm{CKO} / \mathrm{CKO}}$ retinas, compared with controls (Fig. $4 Q)$. Overall we conclude that both conditional mutants recapitulate Hes 1 germline mutant phenotypes regarding loss of proliferating RPCs and excess neurogenesis. However, unlike the previous studies, here, we observed a significant increase in apoptosis, consistent with conditional deletion of Notch1, Rbpj and Dll4 (Yaron et al., 2006; Riesenberg et al., 2009; Zheng et al., 2009; Luo et al., 2012).

To explore the abnormal retinal neuron patterning in Hes1 conditional mutants further, we labeled E16.5 sections with Tubb3, and Mitf, or the nuclear RGC marker Pou4f (Fig. 5). At E16.5, there were many Tubb3 + neurons inappropriately positioned apically, or in the subretinal space, between the retina and RPE cells expressing Mitf (Fig. 5A-C, inset boxes). This phenotype was patchy, with no particular directionality in the nasaltemporal, proximal-distal or dorsal-ventral dimensions. We attribute a missing outer limiting membrane (OLM) previously reported in E14-E16 Hes1 germline mutants, for allowing access to the subretinal space (Takatsuka et al., 2004). To definitively identify the ectopic neurons as RGCs, we labeled E16.5 sections with a pan-Pou $4 \mathrm{f}$ antibody and saw groups of RGC nuclei mispositioned apically (arrow in 5E,F), and in the subretinal space, in both conditional mutants. At P0, H\&E staining highlighted the persistence of outer retinal "gaps" (arrows in Fig. $5 \mathrm{H}, \mathrm{I}$ ). Further analysis at this age was challenging, since lamination defects became difficult to assign as a missing OLM versus formation of a retinal rosette.

\section{Loss of Hes 1 causes a reduction in cone photoreceptor genesis}

Previous work has consistently shown that blocking Notch signaling increases both RGC and cone photoreceptor differentiation (Jadhav et al., 2006b; Yaron et al., 2006; Riesenberg et al., 2009). However, E13.5 Hes1 germline mutant retinas contained fewer Crx + cells (Riesenberg et al., 2009). To address this paradox, we quantified developing cone photoreceptors at three ages: E13.5, E16.5, and P21. First, the Otx2 transcription factor is one of the earliest markers for RPC commitment as a tripotential cell (cone, rod or bipolar) (Nishida et al., 2003; Fossat et al., 2007). Although Otx 2 is also present in adjacent RPE cells, they are easily identifiable by tissue position and shape. So, we quantified Otx2+ optic cup cells in control, Chx10-Cre;Hes $1^{\mathrm{CKO} / \mathrm{CKO}}$ and Rax-Cre; Hes ${ }^{\mathrm{CKO} / \mathrm{CKO}}$ eyes (Fig. $6 A-C, J$ ). We found a significant reduction in the percentage of Otx $2+$ cells in both conditional mutants (Fig. 6J ). To specifically examine cone genesis however, we quantified Thrb2 + cells at E16.5, which is the peak of cone neurogenesis (Fig. 6D-F,K). Here, too, we observed a significant reduction in Thrb $2^{+}$cones in both Chx10-Cre;Hes $1^{\mathrm{CKO} / \mathrm{CKO}}$ and Rax-Cre;Hes $1^{\mathrm{CKO} / \mathrm{CKO}}$ retinas (Fig. $6 K$ ). To address the possibil-

(Figure legend continued.) absence of Hes 7 (K). G-I, L, Anti-Arr3 (cone Arrestin) labeling of P21 further highlighted this reduction of cones $(\boldsymbol{L})$, plus shorter outer segments in the disorganized Arr3 + cones for Rax-Cre; Hes $7^{\text {CKo/CKO }}$ eyes ( $(I)$. L, lens; ONL, outer nuclear layer; INL, inner nuclear layer; GCL, ganglion cell layer. Scale bar, $50 \mu \mathrm{m}$, with boxed insets at $400 \times$ magnification. All graphs display individual data points, mean, and SEM; ${ }^{*} p<0.05$; ${ }^{* *} p<0.01$; ${ }^{* * *} p<0.001 ;{ }^{* * *} p<0.0001 . n=3$ biologic replicates (2 or more sections/replicate quantified) per age and genotype. ity that early loss of Hes 1 only induced a developmental delay, we also quantified Cone Arrestin+ $\left(\mathrm{Carr}^{+}\right)$cells in P21 control, Chx10-Cre;Hes $1^{\mathrm{CKO} / \mathrm{CKO}}$ and Rax-Cre;Hes $1^{\mathrm{CKO} / \mathrm{CKO}}$ eyes (Fig. $6 G-I, L)$. Both conditional mutants contained significantly fewer Carr3 + cells, which was more dramatic in Rax-Cre;Hes 1 CKO/CKO retinas, where the Carr3 + cones had abnormal outer segments (Fig. 6I, arrow, $L$ ). We conclude that canonical Notch signaling does not normally suppress cone photoreceptor genesis, via Hes1 transcriptional repression of cone-promoting genes.

\section{Hes 1 and late-forming retinal cell types}

There has been no evaluation of the requirements for Hes 1 during postnatal retinogenesis, using loss of function mutations. Here we focused on potential P21 phenotypes for INL cell types namely amacrines, bipolars and Müller glia. Given the small size of both conditional mutant retinas (Fig. 2) and irregular ONL architecture, examination of Hes 1 functionality during rod neurogenesis should use different Cre drivers that activate at older ages, with restricted expression to those RPCs giving rise to rods and cones. To estimate the percentage of INL amacrine neurons, we labeled P21 sections with Pax6. However, we found no change upon removal of Hes 1 for either Cre driver (Fig. 7A-C,M). For bipolar neurons, we quantified Vsx2+ nuclei (Fig. $7 D-F, N$ ), where we found a significant increase in both Chx10-Cre; Hes $1^{\mathrm{CKO} / \mathrm{CKO}}$ and Rax-Cre;Hes ${ }^{\mathrm{CKO} / \mathrm{CKO}}$ retinas compared with controls (Fig. $7 N$ ). This was somewhat unanticipated given that in vitro culture of Hes $1^{-1-}$ retinas suggested that fewer bipolar neurons would be produced (Tomita et al., 1996). Finally, we examined Müller glia, which are specialized radial glia that stretch across the retina from apical to basal, with their nuclei in the INL. Numerous studies have shown that loss- or gain-of function mutations in the Notch pathway affect gliogenesis, and that Hes1 is weakly expressed by this cell class (Furukawa et al., 2000; de Melo et al., 2016). We used two different Müller glial markers, Sox9 which is confined to the nucleus and allows for quantification (Fig. 7G-I); and Glutamine Synthetase, a membrane-localized protein that highlights radial glial patterning in the mature retina (Fig. $7 J-L^{\prime}$ ). For Sox9, there was no statistically significant difference in glial cell numbers, among the three genotypes (Fig. 7O). Morphologically, although Sox9+ Müller glia nuclei were aligned normally in the INL (Fig. $7 \mathrm{H}$ ) of Chx10-Cre;Hes $1^{\mathrm{CKO} / \mathrm{CKO}}$ eyes, they were randomly arranged in Rax-Cre;Hes $1^{\mathrm{CKO} / \mathrm{CKO}}$ eyes, including displacement to the ONL (Fig. 7I, arrows).

Next, we examined Müller glial radial morphology. Normally, the apical processes of Müller glia MG photoreceptors form tight junctions at the outer limiting membrane, which is integral with retinal integrity. Given that all Hes 1 mutant embryos have a patchy OLM (Takatsuka et al., 2004), we wondered how this affected mature Müller glial architecture. Glutamine Synthetase expression was normal in Chx10-Cre;Hes1 ${ }^{\mathrm{CKO} / \mathrm{CKO}}$ eyes (cf. Fig. $7 J, J^{\prime}$ and $\left.K, K^{\prime}\right)$. However, in Rax-Cre;Hes ${ }^{\mathrm{CKO} / \mathrm{CKO}}$ retinas Müller glia processes often did not stretch across the apical-basal extent of the retinal layers and appeared to be sparser (Fig. $\left.7 L, L^{\prime}\right)$. Overall, we conclude that Hesl activity is necessary for normal bipolar neuron and Müller glia formation.

\section{Discussion}

The bHLH repressor Hes1 has diverse functions throughout vertebrate development, particularly in the CNS, where it regulates the timing of neurogenesis, the rate of progenitor cell division, gliogenesis, and maintenance of tissue compartment boundaries. These activities correlate with two modes of Hes1 gene expression, low, nonuniform (oscillating) or high, sustained; for exam- 


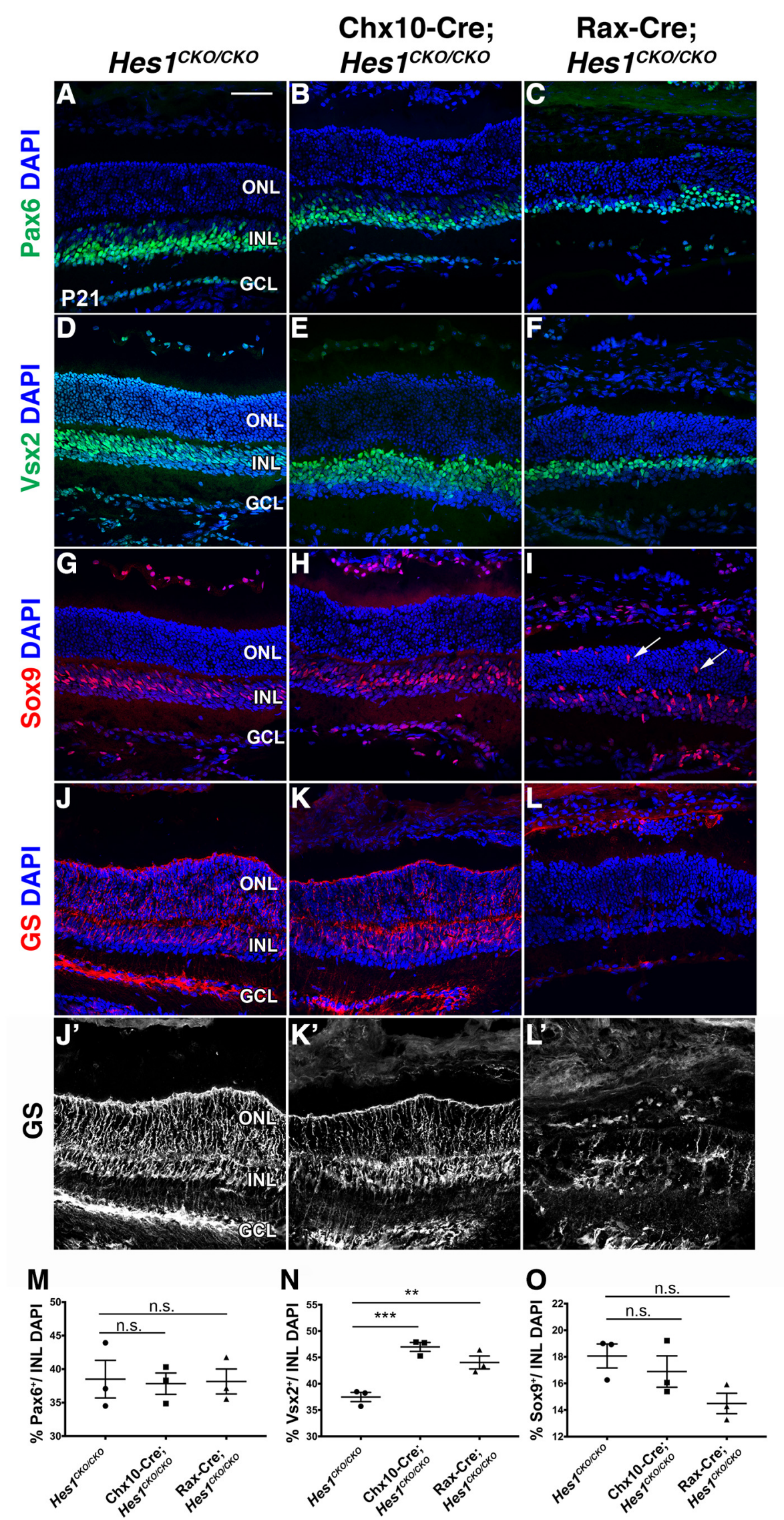

Figure 7. Evaluation of adult inner retinal cell types in Hes 7 retinal mutants. $\boldsymbol{A}-\boldsymbol{C}, \boldsymbol{M}$, The percentage of Pax6 + INL amacrine cells was equivalent among genotypes. $\boldsymbol{D}-\boldsymbol{F}, \boldsymbol{N}$, For bipolar neurons, Vsx2+ nuclei were quantified, although some Müller glial cells also express this protein. The Vsx2+ cells were significantly increased in both Hes 7 mutants $(\boldsymbol{N}) . \mathbf{G}-\boldsymbol{L}^{\prime}, \mathbf{0}$, Two Müller glial markers were evaluated, Sox9 in the nucleus $(\mathbf{G}-\boldsymbol{I})$ and glutamine synthetase in the cell membrane $\left(\boldsymbol{J}-\boldsymbol{L}^{\prime}\right)$. Although the percentage of Sox9+ nuclei was not (Figure legend continues.) 
ple, oscillating Hes1 in neuronal progenitor cells, keeps the pace of cell division, and acts in determining the exit point for differentiation (Shimojo et al., 2008). Here, we extended the known roles of Hes 1 during retinal development, by uncovering an unpredicted requirement in promoting cone photoreceptor and bipolar neuron formation. By comparing and contrasting the spatiotemporal phenotypes induced in two Hes 1 conditional mutants, we also show the embryonic optic nerve head is another CNS location where high, sustained Hes 1 expression maintains a neural-glial boundary. Loss of Hes 1 in this domain resulted in optic nerve coloboma, thereby inserting this gene into the genetic hierarchy regulating optic fissure closure.

\section{Hes1 and embryonic retinogenesis}

It is generally accepted that retinal mutations in the Notch pathway deplete the RPC pool and produce ectopic early-born cell types, namely RGCs and cones. Indeed, we saw that Hes 1 retinal mutants have a significant, early loss of cycling RPCs, and a dramatic increase in RGCs. However, we discovered a substantial loss of cone photoreceptors, which sharply contrasts cone overproduction in other experimental paradigms where Notch signaling is blocked (Jadhav et al., 2006b; Yaron et al., 2006; Riesenberg et al., 2009). We believe that the Hes1 mutant cone phenotype reveals an additional level of regulation for cone genesis. Although it is possible that the substantial loss of cones reflects a change in cell fate, to the benefit of RGCs, this seems unlikely, given the simultaneous increase of RGCs and cones in other Notch retinal mutants. Alternatively, developing cones could be eliminated via apoptosis, in the absence of Hes1. We do not favor this possibility because the percentages of Otx2- and Crx-expressing retinal cells are already abnormally low at E13.5, when photoreceptor production is largely cones (Riesenberg et al., 2009; this paper). Although at E16.5, we noted an increase in apoptosis, it is much milder than the loss of Thrb2+ cones. Finally, Hes genes are normally not present in differentiated cone photoreceptor cells, and Hes5 by itself, has no role in embryonic retinal neurogenesis (Hojo et al., 2000). Previously, we reported an exclusion of Hes5-GFP BAC transgenic expression in nascent embryonic cones (Riesenberg et al., 2018). Moreover, Hes5 expression is upregulated in Hes1 mutants (Hatakeyama et al., 2004) which suggests that the removal of Hes1 releases sufficient Hes5 activity to ectopically squelch cone differentiation. To address this possibility, future experiments will evaluate the early retinal neurogenic phenotypes of mutants lacking multiple Hes genes.

We observed multiple rosette-like cell clusters in both Chx10Cre;Hes $1^{\mathrm{CKO} / \mathrm{CKO}}$ eyes and Rax-Cre;Hes $1^{\mathrm{CKO} / \mathrm{CKO}}$ retinas. Rosettes are mainly composed of photoreceptors, but the exact mechanisms underlying their formation are currently unknown. However, it is possible that the precocious overproduction of RGCs and their incorrect positions in the retina can impact the arrangement of photoreceptors into rosette-like structures, or another aspect of retinal lamination. Indeed, RGC apical to basal migration to create the ganglion cell layer is a critical first step in the progression of retinal lamination. It is plausible that after

$\leftarrow$

(Figure legend continued.) significantly different among the three genotypes $(\boldsymbol{M})$, in Rax-Cre; Hes $7^{\mathrm{CKO} / \mathrm{CK} 0}$ retinas, these cells were frequently misplaced in the ONL (arrows in $I$ ) and had abnormal radial processes $\left(L^{\prime}\right)$. ONL, outer nuclear layer; INL, inner nuclear layer; $G C L$, ganglion cell layer. Scale bar in $\boldsymbol{A}, 50 \mu \mathrm{m}$. Graphs display individual data points, mean, and SEM. n.S., not significant; ${ }^{* *} p<0.01 ;{ }^{* * *} p<0.001 . n=3$ biologic replicates (2 or more sections/replicate quantified) per age and genotype. their final cell division, the nascent RGC nuclei are unable to migrate to their final position, thus become "stuck" at the apical surface of Hes 1 mutant retinas. Another interrelated possibility is that the rapid appearance of excess RGCs simply blocks the available space for RPCs to rise to the apical surface, disrupting cellcell signaling dynamics that include Delta-Notch binding (Norden et al., 2009; Hiscock et al., 2018). In other regions of the CNS, Notch signaling is essential for cortical neuron migration (Hashimoto-Torii et al., 2008), and Hes1 mutants in particular affect the movement of hypothalamic neurons (Aujla et al., 2011). Another consequence of premature RGC neurogenesis appears to also affect the outer limiting membrane (OLM), where extra developing RGCs put pressure on the OLM, inducing localized breaks that allow Pou4f + , Tubb3 + retinal cells to spill into the subretinal space. Subsequently, differentiating photoreceptors may be physically blocked from coalescing apically to initiate the ONL, resulting in their clustering. To understand the cause and effect of RPC, RGC and early photoreceptor cell dynamics requires time-lapse imaging in various control and mutant retinas.

\section{Hes1 and postnatal retinogenesis}

In addition to major changes in cone numbers, we also report a significant increase in bipolar numbers and a trend towards reduced Müller glia number. In the mouse retina, the generation of different retinal cell types follows a temporal sequence, in which bipolar interneurons and Müller glia are generated last, almost entirely during postnatal development. The earlier premature differentiation of RGCs in Hes1 mutants should negatively impact later born cell types, via progressive depletion of the progenitor pool. However, we found a 1.5-fold overproduction of bipolars in both Hes 1 retinal mutants. One explanation could be that in Hes1 mutants, cells that normally develop into Müller glia adopt a bipolar cell fate. Although there is precedent for bipolarMüller glial cell fate switches, for example in Ascl1/Math3(Atoh3) double mutants (Hatakeyama et al., 2001), we did not observe an equivalent, statistically significant loss of Müller glia in either Hes 1 conditional mutants. To provide better evidence for this idea, birthdating studies and possibly Hes 1 deletion with a postnatal-specific Cre driver would be necessary.

\section{Hes 1 and the optic nerve head}

In the vertebrate retina, multiple studies have shown low, nonuniform Hes 1 expression, sometimes termed a "salt and pepper" pattern, within RPCs. There is already precedent that such gene expression generates diversity in an otherwise genetically identical progenitor cell population. In other CNS contexts low, nonuniform Hes1 + cells oscillate, which correlates the promotion of neural stem cell or progenitor cell growth and suppression of differentiation, phenotypes first associated with Hes 1 mutant retinas $>20$ years ago (Tomita et al., 1996). Here, we demonstrate a previously unknown role for Hes 1 in eye formation: that of maintaining the neural-glial boundary at the $\mathrm{ONH}$ via high, sustained Hes 1 protein expression. Interestingly, high-level Hes1 expression is strikingly similar to the stripe of Hairy gene expression separating anterior ocular progenitor cells, from those within the morphogenetic furrow, where photoreceptor differentiation begins in Drosophila eye imaginal discs (Brown et al., 1991). Thus, we are curious to understand whether mammalian high Hes1 expression domains might represent components of an evolutionarily conserved module that could even relate to the regulation of Hairy striped expression in the fly embryo, wing, or leg imaginal discs. 
In the developing optic cup and stalk high, sustained Hes1 initiates at the border between these two compartments, which is a molecular boundary for OC Pax6 and ONH/OS Pax2 expression. Because both genes initially coexpress and then resolve apart in Rax-Cre;Hes $1{ }^{\mathrm{CKO} / \mathrm{CKO}}$ eyes, we conclude that Hes 1 maintains this boundary. Indeed, the initial report of sustained Hes1 expression was at the midbrain-hindbrain boundary (MHB) or isthmus (Baek et al., 2006), which regulates the development and patterning of neighboring brains compartments by secreting Fgf, Wnt and Shh signals (Gibbs et al., 2017). Interestingly these signaling pathways are also important during eye morphogenesis and patterning (Fuhrmann, 2008, 2010; Cavodeassi et al., 2019). Our discovery that Hes 1 is an integral component of the $\mathrm{ONH}$ provokes several questions. First, does its removal result in defective morphogen signaling, and if so, which signaling molecules are affected, and are they sufficient to account for the shift in Pax6-Pax2 border and retinal tissue expansion? Moreover, does the $\mathrm{ONH}$ represent an ocular signaling center, and how does simultaneous signaling become integrated? What seems clear at this point is that Hes 1 regulation of the neural-retinal boundary is independent of canonical Notch signaling, since Rax-Cre deletion of Notch1 or Rbpj removes low Hes1 in RPCs, but not the high Hes1 ONH domain (data not shown).

Interestingly, other mouse mutants exhibit strikingly similar phenotypes to Rax-Cre; Hes1 mutants. Most notably, Pax2 mutant eyes lack both $\mathrm{ONH}$ and OS oligodendrocytes, with these tissues erroneously adopting a neural retinal fate (Schwarz et al., 2000). Vax1/Vax2 double mutants also exhibit retinal expansion tissue into the optic stalk (Take-uchi et al., 2003). In both mutants, the Pax6+ RPE was also expanded, at the expense of the optic stalk, which manifested as a hyperpigmentation that extended proximally toward the midline. Given the similarities of $\mathrm{ONH}$ phenotypes and directly overlapping expression between Hes1 and Pax2, we envision a direct link between these two factors. Because Pax2 expression initiates normally and is sustained in Hes1 mutants, we conclude that Pax2 is upstream of Hes1. Future genetic epistasis testing and molecular profiling experiments will reveal the relationship between these two genes, and identify other factors that act during $\mathrm{ONH}$ formation. We predict that cell adhesion and extracellular matrix genes will be identified through these studies, since these types of proteins are already known to be important during optic fissure closure in vertebrates (Chen et al., 2012; Noh et al., 2016; Gestri et al., 2018; Gordon et al., 2018; Hardy et al., 2019). It will be extremely interesting to integrate Hes 1 into the networks of optic fissure closure and coloboma-associated genes.

\section{References}

Asbreuk CH, van Schaick HS, Cox JJ, Smidt MP, Burbach JP (2002) Survey for paired-like homeodomain gene expression in the hypothalamus: restricted expression patterns of rx, Alx4 and goosecoid. Neuroscience 114: 883-889.

Aujla PK, Bora A, Monahan P, Sweedler JV, Raetzman LT (2011) The notch effector gene Hes1 regulates migration of hypothalamic neurons, neuropeptide content and axon targeting to the pituitary. Dev Biol 353:61-71.

Baek JH, Hatakeyama J, Sakamoto S, Ohtsuka T, Kageyama R (2006) Persistent and high levels of Hes1 expression regulate boundary formation in the developing central nervous system. Development 133:2467-2476.

Brown NL, Sattler CA, Markey DR, Carroll SB (1991) Hairy gene function in the Drosophila eye: normal expression is dispensable but ectopic expression alters cell fates. Development 113:1245-1256.

Brown NL, Kanekar S, Vetter ML, Tucker PK, Gemza DL, Glaser T (1998) Math5 encodes a murine basic helix-loop-helix transcription factor expressed during early stages of retinal neurogenesis. Development 125: $4821-4833$
Cavodeassi F, Creuzet S, Etchevers HC (2019) The hedgehog pathway and ocular developmental anomalies. Hum Genet 138:917-936.

Chen S, Lewis B, Moran A, Xie T (2012) Cadherin-mediated cell adhesion is critical for the closing of the mouse optic fissure. PLoS One 7:e51705.

Clark BS, Stein-O'Brien GL, Shiau F, Cannon GH, Davis-Marcisak E, Sherman T, Santiago CP, Hoang TV, Rajaii F, James-Esposito RE, Gronostajski RM, Fertig EJ, Goff LA, Blackshaw S (2019) Single-cell RNA-seq analysis of retinal development identifies NFI factors as regulating mitotic exit and late-born cell specification. Neuron 102:1111-1126.e5 e1115.

de Melo J, Clark BS, Blackshaw S (2016) Multiple intrinsic factors act in concert with Lhx2 to direct retinal gliogenesis. Sci Rep 6:32757.

Dhanesh SB, Subashini C, James J (2016) Hesl: the maestro in neurogenesis. Cell Mol Life Sci 73:4019-4042.

Fossat N, Le Greneur C, Béby F, Vincent S, Godement P, Chatelain G, Lamonerie T (2007) A new GFP-tagged line reveals unexpected Otx2 protein localization in retinal photoreceptors. BMC Dev Biol 7:122.

Fuhrmann S (2008) Wnt signaling in eye organogenesis. Organogenesis $4: 60-67$.

Fuhrmann S (2010) Eye morphogenesis and patterning of the optic vesicle. Curr Top Dev Biol 93:61-84.

Furukawa T, Kozak CA, Cepko CL (1997) rax, a novel paired-type homeobox gene, shows expression in the anterior neural fold and developing retina. Proc Natl Acad Sci U S A 94:3088-3093.

Furukawa T, Mukherjee S, Bao ZZ, Morrow EM, Cepko CL (2000) rax, Hes1, and notch1 promote the formation of Muller glia by postnatal retinal progenitor cells. Neuron 26:383-394.

Gestri G, Bazin-Lopez N, Scholes C, Wilson SW (2018) Cell behaviors during closure of the choroid fissure in the developing eye. Front Cell Neurosci 12:42.

Gibbs HC, Chang-Gonzalez A, Hwang W, Yeh AT, Lekven AC (2017) Midbrain-hindbrain boundary morphogenesis: at the intersection of wnt and fgf signaling. Front Neuroanat 11:64.

Gordon HB, Lusk S, Carney KR, Wirick EO, Murray BF, Kwan KM (2018) Hedgehog signaling regulates cell motility and optic fissure and stalk formation during vertebrate eye morphogenesis. Development 145: $\operatorname{dev} 165068$.

Hardy H, Prendergast JG, Patel A, Dutta S, Trejo-Reveles V, Kroeger H, Yung AR, Goodrich LV, Brooks B, Sowden JC, Rainger J (2019) Detailed analysis of chick optic fissure closure reveals Netrin-1 as an essential mediator of epithelial fusion. Elife 8:e43877.

Harima Y, Imayoshi I, Shimojo H, Kobayashi T, Kageyama R (2014) The roles and mechanism of ultradian oscillatory expression of the mouse hes genes. Semin Cell Dev Biol 34:85-90.

Hashimoto-Torii K, Torii M, Sarkisian MR, Bartley CM, Shen J, Radtke F, Gridley T, Sestan N, Rakic P (2008) Interaction between reelin and notch signaling regulates neuronal migration in the cerebral cortex. Neuron 60:273-284.

Hatakeyama J, Tomita K, Inoue T, Kageyama R (2001) Roles of homeobox and bHLH genes in specification of a retinal cell type. Development 128: 1313-1322.

Hatakeyama J, Bessho Y, Katoh K, Ookawara S, Fujioka M, Guillemot F, Kageyama R (2004) Hes genes regulate size, shape and histogenesis of the nervous system by control of the timing of neural stem cell differentiation. Development 131:5539-5550.

Hirata H, Yoshiura S, Ohtsuka T, Bessho Y, Harada T, Yoshikawa K, Kageyama R (2002) Oscillatory expression of the bHLH factor Hes1 regulated by a negative feedback loop. Science 298:840-843.

Hiscock TW, Miesfeld JB, Mosaliganti KR, Link BA, Megason SG (2018) Feedback between tissue packing and neurogenesis in the zebrafish neural tube. Development 145:dev157040.

Hojo M, Ohtsuka T, Hashimoto N, Gradwohl G, Guillemot F, Kageyama R (2000) Glial cell fate specification modulated by the bHLH gene Hes5 in mouse retina. Development 127:2515-2522.

Hutcheson DA, Hanson MI, Moore KB, Le TT, Brown NL, Vetter ML (2005) bHLH-dependent and -independent modes of Ath5 gene regulation during retinal development. Development 132:829-839.

Imayoshi I, Kageyama R (2014) Oscillatory control of bHLH factors in neural progenitors. Trends Neurosci 37:531-538.

Imayoshi I, Shimogori T, Ohtsuka T, Kageyama R (2008) Hes genes and neurogenin regulate non-neural versus neural fate specification in the dorsal telencephalic midline. Development 135:2531-2541.

Imayoshi I, Isomura A, Harima Y, Kawaguchi K, Kori H, Miyachi H, Fujiwara 
T, Ishidate F, Kageyama R (2013) Oscillatory control of factors determining multipotency and fate in mouse neural progenitors. Science 342:1203-1208.

Ishibashi M, Ang SL, Shiota K, Nakanishi S, Kageyama R, Guillemot F (1995) Targeted disruption of mammalian hairy and enhancer of split homolog-1 (HES-1) leads to up-regulation of neural helix-loop-helix factors, premature neurogenesis, and severe neural tube defects. Genes Dev 9:3136-3148

Jadhav AP, Cho SH, Cepko CL (2006a) Notch activity permits retinal cells to progress through multiple progenitor states and acquire a stem cell property. Proc Natl Acad Sci U S A 103:18998-19003.

Jadhav AP, Mason HA, Cepko CL (2006b) Notch 1 inhibits photoreceptor production in the developing mammalian retina. Development 133: 913-923.

Jensen MH, Sneppen K, Tiana G (2003) Sustained oscillations and time delays in gene expression of protein Hes1. FEBS Lett 541:176-177.

Kageyama R, Ohtsuka T, Kobayashi T (2007) The hes gene family: repressors and oscillators that orchestrate embryogenesis. Development 134: 1243-1251.

Kageyama R, Ohtsuka T, Kobayashi T (2008) Roles of hes genes in neural development. Dev Growth Differ 50:S97-S103.

Kameda Y, Saitoh T, Fujimura T (2011) Hes1 regulates the number and anterior-posterior patterning of mesencephalic dopaminergic neurons at the mid/hindbrain boundary (isthmus). Dev Biol 358:91-101.

Klimova L, Kozmik Z (2014) Stage-dependent requirement of neuroretinal Pax6 for lens and retina development. Development 141:1292-1302.

Klimova L, Lachova J, Machon O, Sedlacek R, Kozmik Z (2013) Generation of $\mathrm{mRx}$-cre transgenic mouse line for efficient conditional gene deletion in early retinal progenitors. PLoS One 8:e63029.

Kovall RA, Gebelein B, Sprinzak D, Kopan R (2017) The canonical notch signaling pathway: structural and biochemical insights into shape, sugar, and force. Dev Cell 41:228-241.

Lee HY, Wroblewski E, Philips GT, Stair CN, Conley K, Reedy M, Mastick GS, Brown NL (2005) Multiple requirements for hes 1 during early eye formation. Dev Biol 284:464-478.

Liu ZH, Dai XM, Du B (2015) Hes1: a key role in stemness, metastasis and multidrug resistance. Cancer Biol Ther 16:353-359.

Livesey FJ, Cepko CL (2001) Vertebrate neural cell-fate determination: lessons from the retina. Nat Rev Neurosci 2:109-118.

Luo H, Jin K, Xie Z, Qiu F, Li S, Zou M, Cai L, Hozumi K, Shima DT, Xiang M (2012) Forkhead box N4 (Foxn4) activates Dll4-notch signaling to suppress photoreceptor cell fates of early retinal progenitors. Proc Natl Acad Sci U S A 109:E553-E562.

Madisen L, Zwingman TA, Sunkin SM, Oh SW, Zariwala HA, Gu H, Ng LL, Palmiter RD, Hawrylycz MJ, Jones AR, Lein ES, Zeng H (2010) A robust and high-throughput cre reporting and characterization system for the whole mouse brain. Nat Neurosci 13:133-140.

Mastick GS, Andrews GL (2001) Pax6 regulates the identity of embryonic diencephalic neurons. Mol Cell Neurosci 17:190-207.

Mathers PH, Grinberg A, Mahon KA, Jamrich M (1997) The rx homoeobox gene is essential for vertebrate eye development. Nature 387:603-607.

Miesfeld JB, Glaser T, Brown NL (2018) The dynamics of native Atoh7 protein expression during mouse retinal histogenesis, revealed with a new antibody. Gene Expr Patterns 27:114-121.

Nakamura Y, Sakakibara Si, Miyata T, Ogawa M, Shimazaki T, Weiss S, Kageyama R, Okano H (2000) The bHLH gene hes1 as a repressor of the neuronal commitment of CNS stem cells. J Neurosci 20:283-293.

Nishida A, Furukawa A, Koike C, Tano Y, Aizawa S, Matsuo I, Furukawa T (2003) Otx2 homeobox gene controls retinal photoreceptor cell fate and pineal gland development. Nat Neurosci 6:1255-1263.

Noh H, Lee H, Park E, Park S (2016) Proper closure of the optic fissure requires ephrin A5-EphB2-JNK signaling. Development 143:461-472.

Norden C, Young S, Link BA, Harris WA (2009) Actomyosin is the main driver of interkinetic nuclear migration in the retina. Cell 138:1195-1208.
Ohtsuka T, Sakamoto M, Guillemot F, Kageyama R (2001) Roles of the basic helix-loop-helix genes Hes1 and Hes5 in expansion of neural stem cells of the developing brain. J Biol Chem 276:30467-30474.

Ohyama T, Groves AK (2004) Generation of Pax2-cre mice by modification of a Pax2 bacterial artificial chromosome. Genesis 38:195-199.

Otteson DC, Shelden E, Jones JM, Kameoka J, Hitchcock PF (1998) Pax2 expression and retinal morphogenesis in the normal and krd mouse. Dev Biol 193:209-224.

Pak T, Yoo S, Miranda-Angulo AM, Wang H, Blackshaw S (2014) RaxCreERT2 knock-in mice: a tool for selective and conditional gene deletion in progenitor cells and radial glia of the retina and hypothalamus. PLoS One 9:e90381.

Riesenberg AN, Brown NL (2016) Cell autonomous and nonautonomous requirements for Delltalike1 during early mouse retinal neurogenesis. Dev Dyn 245:631-640.

Riesenberg AN, Liu Z, Kopan R, Brown NL (2009) Rbpj cell autonomous regulation of retinal ganglion cell and cone photoreceptor fates in the mouse retina. J Neurosci 29:12865-12877.

Riesenberg AN, Conley KW, Le TT, Brown NL (2018) Separate and coincident expression of Hes1 and Hes5 in the developing mouse eye. Dev Dyn 247:212-221.

Rowan S, Cepko CL (2004) Genetic analysis of the homeodomain transcription factor Chx10 in the retina using a novel multifunctional BAC transgenic mouse reporter. Dev Biol 271:388-402.

Schwarz M, Cecconi F, Bernier G, Andrejewski N, Kammandel B, Wagner M, Gruss P (2000) Spatial specification of mammalian eye territories by reciprocal transcriptional repression of Pax2 and Pax6. Development 127:4325-4334.

Shimojo H, Ohtsuka T, Kageyama R (2008) Oscillations in notch signaling regulate maintenance of neural progenitors. Neuron 58:52-64.

Solecki DJ, Liu XL, Tomoda T, Fang Y, Hatten ME (2001) Activated Notch2 signaling inhibits differentiation of cerebellar granule neuron precursors by maintaining proliferation. Neuron 31:557-568.

Takatsuka K, Hatakeyama J, Bessho Y, Kageyama R (2004) Roles of the bHLH gene Hes1 in retinal morphogenesis. Brain Res 1004:148-155.

Take-uchi M, Clarke JD, Wilson SW (2003) Hedgehog signalling maintains the optic stalk-retinal interface through the regulation of vax gene activity. Development 130:955-968.

Tao C, Zhang X (2014) Development of astrocytes in the vertebrate eye. Dev Dyn 243:1501-1510.

Tomita K, Ishibashi M, Nakahara K, Ang SL, Nakanishi S, Guillemot F, Kageyama R (1996) Mammalian hairy and enhancer of split homolog 1 regulates differentiation of retinal neurons and is essential for eye morphogenesis. Neuron 16:723-734.

Torres M, Gómez-Pardo E, Gruss P (1996) Pax2 contributes to inner ear patterning and optic nerve trajectory. Development 122:3381-3391.

Uriu K (2016) Genetic oscillators in development. Dev Growth Differ $58: 16-30$.

Wall DS, Mears AJ, McNeill B, Mazerolle C, Thurig S, Wang Y, Kageyama R, Wallace VA (2009) Progenitor cell proliferation in the retina is dependent on notch-independent sonic hedgehog/Hesl activity. J Cell Biol 184:101-112.

Wataya T, Ando S, Muguruma K, Ikeda H, Watanabe K, Eiraku M, Kawada M, Takahashi J, Hashimoto N, Sasai Y (2008) Minimization of exogenous signals in ES cell culture induces rostral hypothalamic differentiation. Proc Natl Acad Sci U S A 105:11796-11801.

Yaron O, Farhy C, Marquardt T, Applebury M, Ashery-Padan R (2006) Notch1 functions to suppress cone-photoreceptor fate specification in the developing mouse retina. Development 133:1367-1378.

Zheng MH, Shi M, Pei Z, Gao F, Han H, Ding YQ (2009) The transcription factor RBP-J is essential for retinal cell differentiation and lamination. Mol Brain 2:38. 